\title{
Strength and Vulnerability: Indirect Effects of Age on Changes in Occupational Well-Being through Emotion Regulation and Physiological Disease
}

\author{
Hannes Zacher ${ }^{1}$ and Cort W. Rudolph ${ }^{2}$ \\ ${ }^{1}$ Wilhelm Wundt Institute of Psychology, Leipzig University, Germany \\ ${ }^{2}$ Department of Psychology, Saint Louis University
}

(C) 2021, American Psychological Association. This paper is not the copy of record and may not exactly replicate the final, authoritative version of the article. Please do not copy or cite without authors permission. The final article will be available, upon publication, via its DOI: https://doi.org/10.1037/pag0000671

This article is in press at Psychology and Aging https://www.apa.org/pubs/journals/pag). It is a post-review pre-publication version of the manuscript. Please cite as:

Zacher, H. \& Rudolph, C. W. (in press). Strength and vulnerability: Indirect effects of age on changes in occupational well-being through emotion regulation and physiological disease. Psychology and Aging. https://doi.org/10.1037/pag0000671

\section{Author Note}

Hannes Zacher (iD https://orcid.org/0000-0001-6336-2947

Cort W. Rudolph (iD https://orcid.org/0000-0002-0536-9638

The study reported in this article is funded by Volkswagen Foundation (Az. 96 849, "The Role of Work in the Development of Civilization Diseases"). The authors have no conflicts of interest to disclose. The study design, hypotheses, and analytic plan were not preregistered. The de-identified data on which the study conclusions are based, the analytic code needed to reproduce analyses, and the study materials are available at https://osf.io/myd7u/.

Correspondence concerning this article should be addressed to Hannes Zacher, Wilhelm Wundt Institute of Psychology, Leipzig University, Neumarkt 9-19, 04109 Leipzig, Germany. Email: hannes.zacher@uni-leipzig.de 


\begin{abstract}
The strength and vulnerability integration (SAVI) model posits that development across the adult lifespan is accompanied by improvements in emotion regulation and declines in physiological flexibility. Due to these age-related changes, emotional well-being is expected to be higher among older (vs. younger) adults when they experience no or only minor stressors. In contrast, more intense stressors should lead to lower well-being among older adults. We develop and test a conceptual model based on the SAVI model in the work context that focuses on experienced incivility as a moderator of the indirect effects of employee age on changes in two indicators of occupational well-being (i.e., job satisfaction, emotional exhaustion) through emotion regulation and physiological disease. Experienced incivility is a workplace stressor that may weaken the beneficial effects of emotion regulation and intensify the detrimental effects of physiological disease. Data were collected from 781 employees across three time points, spanning four months. Results showed that age had indirect effects on (a) increases in job satisfaction through emotion regulation, (b) decreases in emotional exhaustion through emotion regulation, (c) decreases in job satisfaction through physiological disease, and (d) increases in emotional exhaustion through physiological disease. Out of four hypothesized interaction effects, only the indirect effect of age on decreases in emotional exhaustion through emotion regulation was, as expected, weaker and non-significant when experienced incivility was high (vs. low). These findings provide partial support for our model and imply that future theory development on age and occupational wellbeing should consider both age-related strengths and vulnerabilities.

Keywords: age; emotion regulation; physiological disease; incivility; occupational well-being
\end{abstract}




\section{Public Significance Statement}

Older employees reported higher emotion regulation and physiological disease than younger employees. Emotion regulation was associated with increases in job satisfaction and decreases in emotional exhaustion, whereas physiological disease was associated with decreases in job satisfaction and increases in exhaustion across three months. The link between emotion regulation and exhaustion was weaker when workplace incivility was high. These findings highlight the role of age-related strengths and vulnerabilities for occupational well-being. 


\section{Strength and Vulnerability: Indirect Effects of Age on Changes in Occupational Well-Being through Emotion Regulation and Physiological Disease}

As workforces are aging around the globe, organizational researchers and practitioners have become increasingly interested in relationships between employee age and occupational well-being outcomes (Schmitt \& Bathen, 2015; Zacher, 2020). Research has found, on average, positive associations between age and various indicators of occupational well-being, such as positive affect and job satisfaction (Ng \& Feldman, 2010; Scheibe et al., 2019), and negative associations between age and strain outcomes, such as negative affect and emotional exhaustion (Ng \& Feldman, 2010, 2013). These findings are consistent with theory and empirical evidence in the lifespan development literature (Charles \& Carstensen, 2010; Scheibe \& Carstensen, 2010), which suggests that older adults generally experience more positive emotions and higher emotional well-being, and less negative emotions and strain than younger adults.

Notwithstanding theoretical explanations offered by the lifespan literature (e.g., Carstensen et al., 2003; Charles \& Luong, 2013), the mechanisms and boundary conditions of relations between age and occupational well-being outcomes are not well understood. First, both theory and research suggest that the aging process is associated with changes in multiple domains of functioning (e.g., emotion regulation, physiological flexibility) that may impact on occupational well-being (Jiang \& Fung, 2019; Scheibe \& Zacher, 2013). Importantly, some of these mechanisms represent vulnerabilities of older adults (i.e., decreases in favorable characteristics with age) and, thus, could reduce well-being at higher ages. For instance, a metaanalysis found positive associations between employee age and several indicators of ill-health (e.g., blood pressure, cholesterol level; Ng \& Feldman, 2013). A focus on the positive overall relationships between age and occupational well-being outcomes may suggest that aging is only 
associated with mechanisms representing strengths, but not vulnerabilities of older adults. A neglect of such vulnerabilities may prevent a more complete understanding of associations between age and occupational well-being. Therefore, it is important to conduct theory-based studies of multiple and potentially divergent age-related mechanisms of these relations.

Second, the magnitude of the indirect effects of age on occupational well-being outcomes through age-related mechanisms may depend on (perceived) characteristics of the work context. Research has suggested that older employees are able to deal more effectively with work-related stressors than younger employees because they have better emotion regulation skills (Doerwald et al., 2016; Johnson et al., 2013). However, it remains unclear how work stressors may interact with age-related mechanisms representing both strengths and vulnerabilities of older employees in predicting occupational well-being. Specifically, it may be possible that certain mechanisms are more or less strongly associated with well-being when work stressors are high or low.

The goal of this study is to develop and test a conceptual model (see Figure 1) of the indirect effects of employee age on changes in job satisfaction and emotional exhaustion based on the strength and vulnerability integration (SAVI) model (Charles, 2010; Charles \& Luong, 2013). The SAVI model focuses on age-related changes in emotional well-being, broadly defined as people's subjective emotional experience (e.g., self-reports of positive and negative affect, life satisfaction; Charles, 2010). We adapt and extend the SAVI model to the work context by focusing on two emotionally-relevant indicators of occupational well-being (Schmitt et al., 2012). Job satisfaction has been defined as "a pleasurable or positive emotional affective state resulting from the appraisal of one's job or job experiences" (Locke, 1976, p. 1300; see also Brief \& Weiss, 2002). Emotional exhaustion is a key dimension of the job burnout construct and entails feelings of emotional depletion and fatigue due to work-related experiences (Maslach \& 
Jackson, 1981; Maslach et al., 2001). Job satisfaction and emotional exhaustion are important work-related well-being outcomes because they have been shown to predict employees' general well-being (i.e., life satisfaction, depressive symptoms), job performance, and turnover (Hakanen \& Schaufeli, 2012; Judge \& Watanabe, 1993; Wright \& Cropanzano, 1998).

As age-related mechanisms, we focus on emotion regulation and physiological disease. Emotion regulation entails the use of strategies to control one's emotions in stressful situations, and has been described as a strength of older employees (Doerwald et al., 2016; Scheibe \& Zacher, 2013). Physiological disease in this study includes having diagnosed cardiovascular problems, musculoskeletal problems, and hormonal and metabolic disease, which are generally more likely among older employees and, thus, represent vulnerabilities at higher ages (Ilmarinen et al., 1997; Ng \& Feldman, 2013). We use physiological disease as a proxy for physiological flexibility as per the SAVI model. Age-related physiological disease is strongly and negatively related to physiological flexibility (Rozanski \& Kubzansky, 2005), and meta-analytic evidence suggests that physical health is negatively related to heart rate and blood pressure reactivity and positively related to heart rate recovery from acute psychological stressors (Forcier et al., 2006).

We examine experienced incivility at work as a potential boundary condition of the indirect effects of age on changes in occupational well-being outcomes. Experienced incivility is a common, uncontrollable, and relentless workplace stressor, which entails employees facing more or less subtle mistreatment, often with ambiguous intent to harm the target, and varying degrees of "micro-aggressions" by other people at their workplace (Cortina et al., 2001; Schilpzand et al., 2016). Examples include receiving inappropriate comments from supervisors or coworkers, being treated in a condescending and disrespectful way, and being ignored or excluded at work. We included experienced incivility as a workplace stressor in our conceptual 
model because the SAVI model suggests that (potential) social exclusion is an important stressor among older adults (Charles, 2010). Research suggests that incivility is also a central stressor at work because it threatens core human needs for belongingness and control (Leiter et al., 2015).

\section{Strength and Vulnerability Integration Model}

The SAVI model explains how the aging process is associated with adults' emotional well-being during three time periods—-before and after a stressful event (i.e., general well-being) and during a stressful event (Charles, 2010). Three recent studies on work-related phenomena have drawn on the SAVI model. However, these studies either did not focus on well-being or the underlying age-related mechanisms proposed by the SAVI model (Amarnani et al., 2019; Marchiondo et al., 2019) or did not find evidence for SAVI-consistent strength and vulnerability effects (Reh et al. 2021). This is perhaps because these studies did not test conceptual models that reflect key tenets of the SAVI model. Indeed, to advance research and practice on age and work, it is essential to examine a comprehensive model including mechanisms and boundary conditions of relationships between age and occupational well-being outcomes. To this end, the SAVI model posits two pathways: a strength pathway and a vulnerability pathway.

\section{Strength Pathway}

First, based on lifespan theories of emotion and motivation (e.g., Blanchard-Fields, 2007; Carstensen, 1995), the SAVI model proposes that age is positively related to the frequency and successful use of emotion regulation strategies. This age-related strength explains why older as compared to younger adults generally experience higher well-being in everyday life or when only experiencing short-lived "exposure to minor irritations and setbacks" (Charles, 2010, p. 1068). The model further suggests that, during a stressful event, the positive effects of this strength on well-being are mitigated. According to Charles (2010), "Situations in which people 
cannot easily employ these skills include times when they encounter the threat or loss of social belonging, the continued exposure to chronic unrelenting stressors, and neurobiological dysregulation that makes employing skills to avoid distress difficult if not impossible" (p. 1069).

Thus, we argue that employee age is generally positively related to emotion regulation (see also Doerwald et al., 2016); in turn, higher emotion regulation should be related to increases in job satisfaction and decreases in emotional exhaustion when experienced workplace incivility is low (vs. high). Consistent with the SAVI model and research on emotion regulation as a personal resource (Buruck et al., 2016; Lawrence et al., 2011), we expect that employees who make greater use of emotion regulation strategies are more likely to experience positive emotional states in the work role (i.e., job satisfaction) and are less likely to feel depleted from their work experiences (i.e., emotional exhaustion) when experienced incivility is low. In these situations, older employees should experience higher job satisfaction and lower emotional exhaustion than younger employees due to their higher emotion regulation skills.

However, based on the SAVI model, we also expect that the positive association between emotion regulation and job satisfaction, the negative association between emotion regulation and emotional exhaustion, as well as the indirect effects of age on occupational well-being outcomes are attenuated when experienced incivility is high (e.g., when employees are verbally mistreated or socially excluded by supervisors or coworkers). Thus, when employees are faced with this uncontrollable and unrelenting workplace stressor, the use of emotion regulation skills should be less effective for bolstering their occupational well-being. In summary, we expect a "secondstage moderation" effect of experienced incivility in our conceptual model (see Figure 1). Hypothesis 1: Experienced incivility moderates the indirect effect of age on change in job satisfaction through emotion regulation, such that the positive indirect effect is stronger when 
experienced incivility is low and weaker when experienced incivility is high.

Hypothesis 2: Experienced incivility moderates the indirect effect of age on change in emotional exhaustion through emotion regulation, such that the negative indirect effect is stronger when experienced incivility is low and weaker when experienced incivility is high.

\section{Vulnerability Pathway}

The second pathway leading from age to emotional well-being proposed by the SAVI model entails that age-related changes in physiology, such as increased cardiovascular problems and the slowing down of the autonomous nervous system, lead to reduced physiological flexibility (or reactivity) among older adults. Accordingly, older adults are assumed to have greater difficulty modifying their physiological arousal in response to stressful events_resulting in, for instance, prolonged increases in blood pressure and reduced recovery (Charles, 2010). Thus, the SAVI model posits that age-related declines in physiological flexibility lead to reduced well-being when older adults experience stressful events, whereas this vulnerability is not expected to impact upon their well-being when no or only minor stressors are present.

Accordingly, we further propose that experienced workplace incivility moderates the indirect effects of age on increases in job satisfaction and decreases in emotional exhaustion through physiological disease. We expect that, due to physical and physiological changes with aging (Maertens et al., 2012), employee age is generally positively related to physiological disease; in turn, greater physiological disease should relate to decreases in job satisfaction and to increases in emotional exhaustion when experienced incivility is high (vs. low). Thus, as for the strength pathway, we expect a "second-stage moderation" effect, such that high levels of experienced incivility strengthen the otherwise weak relationships between physiological disease and occupational well-being outcomes, as well as the otherwise weak indirect effects of age on 
these outcomes through physiological disease.

Based on propositions of the SAVI model, and consistent with research on the effects of physiological disease on reactivity to stress (Forcier et al., 2006) and of physical health on wellbeing (Karunamuni et al., 2021), we expect that employees who report greater physiological disease are less likely to experience positive emotional states in the work role (i.e., job satisfaction) and more likely to feel depleted from their work experiences (i.e., emotional exhaustion) when experienced incivility is high. Thus, older employees, who are more likely to have physiological diseases, should experience decreased job satisfaction and increased emotional exhaustion when faced with this relentless work stressor, whereas younger employees should be less impacted. However, drawing on the SAVI model, we expect that the negative association between physiological disease and job satisfaction and the positive association between physiological disease and exhaustion are attenuated when experienced incivility is low. Hypothesis 3: Experienced incivility moderates the indirect effect of age on change in job satisfaction through physiological disease, such that the negative indirect effect is stronger when experienced incivility is high and weaker when experienced incivility is low.

Hypothesis 4: Experienced incivility moderates the indirect effect of age on change in emotional exhaustion through physiological disease, such that the positive indirect effect is stronger when experienced incivility is high and weaker when experienced incivility is low.

\section{Method}

\section{Transparency and Openness}

In service of transparency and openness, the de-identified data on which the study conclusions are based, the analytic code needed to reproduce the analyses in $\mathrm{R}$, the study materials, and complete results of all focal as well as supplemental analyses are available in an 
online appendix at the Open Science Framework: https://osf.io/myd7u/.

\section{Participants and Procedure}

Data were collected at three time points, across four months (Time [T] 1 at the beginning of July, T2 at the beginning of August, and T3 at the beginning of November 2018). Employee age, emotion regulation, and physiological disease were measured only at $\mathrm{T} 1$. We did not measure these variables at T2 and T3 because age is exogenous to the mediator variables (i.e., reverse causality is not a problem) and because we focus on interindividual differences and not intraindividual changes (e.g., aging) in these variables. The second-stage moderator, experienced incivility, was assessed at T2 and, to examine test-retest reliability, at T3. The outcomes, job satisfaction and emotional exhaustion, were also measured at T2 and T3, but not at T1. Data for this study were collected as part of a larger data collection effort, and so far one other study based on the same dataset, but with a completely different research question and different substantive variables, has been published (Weiss \& Zacher, 2021). This research was conducted in line with the ethical guidelines and requirements of the German Psychological Society.

We commissioned a professional and ISO 26362 certified panel provider to recruit participants from a nationally representative online panel. To be eligible to participate, participants had to be at least 18 years old and be working full-time. Approximately 3,500 participants were initially contacted with a request to participate at $\mathrm{T} 1$. This number of initial participants was determined based on the panel provider's recommendations to obtain a final sample size of 750 participants or more at T3, which is sufficient to detect small correlational effect sizes (i.e., $r \geq .10$; Cohen, 1988) with high (i.e., $\geq .80$ ) statistical power. Of those 3,500 contacted, 1,522 responded and were eligible to participate according to our selected inclusion criteria. Of these 1,522 who qualified, 781 consented to participate and provided complete data 
on the substantive variables of interest at all three measurement occasions, thus constituting the final sample. Participants $(43.40 \%$ female) were on average 43.70 years old $(S D=10.60)$ and had 15.50 years of professional experience $(S D=11.40)$. Race/ethnicity of participants was not assessed. Most participants held either upper secondary (18.10\%) or (technical) college/university degrees (40.10\%). The median household income for participants was $€ 3000.00 /$ month. Participants worked in a wide array of industries, with most participants employed in public administration ( $n=107 ; 13.70 \%)$, manufacturing $(n=91 ; 11.70 \%)$, human health and social work activities $(n=80 ; 10.20 \%)$, “other" service activities $(n=76 ; 9.70 \%)$, and information and communication $(n=59 ; 7.60 \%)$. A summary of participant demographics is shown in Table 1 .

Across the three measurement waves of this study, some participant attrition was observed. Initially, $n=1,522$ participants provided complete responses at T1. Thus, the effective T3 response rate for the $n=781$ panel considered here is $51.31 \%$. To understand the nature of attrition, we compared T1-only responders with panel responders on a number of demographic and substantive variables measured at T1. As reported in Table 1, there were some differences between complete and incomplete responders (e.g., the complete panel was somewhat older than the incomplete responders). We followed up these comparisons by conducting a logistic regression model predicting attrition status (i.e., incomplete vs. complete responders). Only age $(\mathrm{OR}=1.02,95 \% \mathrm{CI}: 1.00$ to 1.03$)$ and emotion regulation $(\mathrm{OR}=1.28,95 \% \mathrm{CI}: 1.10$ to 1.50$)$ differentiated response patterns, with older respondents and those with higher levels of emotion regulation being associated with a higher likelihood of being a "complete responder." However, we note that this model only accounted for a small percentage of the variance explained in response pattern $\left(R^{2}\right.$ Cox-Snell $\left.=.023\right)$. Given this small effect, we are comfortable suggesting that attrition was not a primary concern for this study. 


\section{Measures}

To assess most constructs in our conceptual model, we used shortened scales with three or four items due to constraints in survey time. Unless indicated otherwise, we selected items with the highest factor loadings in the respective scale development study (Stanton et al., 2002). To validate the shortened scales, we conducted a validation study with $N=70$ full-time workers recruited via Amazon's Mechanical Turk platform, in which we administered the full original scales (the data and descriptive statistics of the validation study are available via our online appendix). Below, we report the correlations between these scales for each construct.

Emotion Regulation. We used the three highest loading items from the 7-item selffocused emotion regulation subscale of the Rotterdam emotional intelligence scale (Pekaar et al., 2018) to measure emotion regulation at T1. The items are, "I am in control of my own emotions," "I can suppress my emotions easily," and "I do not let my emotions take over." The response scale ranged from 1 (not true at all) to 5 (completely true). Reliability for the scale was $\operatorname{good}(\alpha=.736, \omega=.738, \mathrm{AVE}=.487)$. In the validation study, the 3 -item scale $(M=3.85, S D=$ $.80)$ was highly correlated $(r=.91, p<.001)$ with the full 7-item scale $(M=3.82, S D=.68)$.

Physiological Disease. We used three health symptoms from the work ability index (Tuomi et al., 1998) to assess three common age-related physiological diseases at T1 (see Charles, 2010). Participants were asked to report whether they had been diagnosed with “cardiovascular diseases (e.g., heart disease)," "hormone/metabolic diseases (e.g., diabetes)," and "disorders of the musculoskeletal system of the back, limbs or other parts of the body (e.g., rheumatism)." For each symptom, participants were asked to indicate 0 (symptom does not exist) or 1 (symptom diagnosed by a doctor) and we created an overall physiological disease score by summing responses across items. This measure demonstrated relatively low internal consistency 
reliability $(\alpha=.473, \omega=.477, \mathrm{AVE}=.233)$, which is not surprising for a "health symptoms checklist" type of measure (Ware et al., 1998). Physiological disease has been considered by some as a formative construct, for which items do not have to be highly intercorrelated (n.b., correlations among diseases observed here range from $r_{\mathrm{xy}}=.208-.281, p \mathrm{~s}<.05$; see Diamantopoulos et al., 2008; R. D. Howell et al., 2007). Consistently, research on the work ability index has suggested that test-retest reliability may be a more appropriate method to gauge the measure's reliability than internal consistency reliability. Such research has shown the testretest reliability of the measure to be adequate (De Zwart et al., 2002). Supporting the age-graded nature of these physiological diseases, we found significant $(p<.05)$, positive correlations between age and each specific disease (i.e., cardiovascular: $r_{x y}=.217$; hormone $/$ metabolic: $r_{x y}=$ .318; musculoskeletal: $r_{x y}=.147$; see online appendix for complete details).

Experienced Incivility. We used three items from Blau and Andersson (2005) to assess experienced incivility at T2 and T3. For each item, participants were asked to indicate, "How often someone at work has done the following to you during the past month?" The items were, "made demeaning, rude, or derogatory remarks about you," "addressed you in unprofessional terms, either privately or publicly," and "ignored or excluded you from professional camaraderie (e.g., social conversation)." Participants provided their responses on a scale ranging from 1 (never) to 5 (always). This measure demonstrated good reliability at T2 $(\alpha=.905, \omega=.906$, $\mathrm{AVE}=.763)$ and $\mathrm{T} 3(\alpha=.921, \omega=.922, \mathrm{AVE}=.798)$. In the validation study, the 3 -item scale $(M=1.40, S D=.48)$ was highly correlated $(r=.89, p<.001)$ with the full 7 -item scale $(M=$ $1.50, S D=.50)$

In our survey, we included the full 7-item scale by Blau and Andersson (2005). We initially fitted our focal model to all seven items, which resulted in poor model fit. Therefore, we 
sought a shorter version of this scale to make the model more parsimonious by reducing the number of estimated parameters. To this end, we applied the OASIS procedure recently developed by Cortina et al. (2020) to produce a three-item subset that maximized internal consistency reliability. The three items described above resulted in the optimal subset of items in terms of internal consistency estimates, and related indices of reliability (i.e., $\lambda_{2}=.850 ; r_{\text {part-whole }}$ $=.962$ ). This three-item structure was also supported by confirmatory factor analysis (i.e., these three items demonstrated the highest standardized factor loadings amongst the seven items of the full scale). We cross-validated the three-item scale against the same items collected at T3, and fully replicated our findings with respect to items selected, their reliabilities, and factor structure/strength of factor loadings. The test-retest reliability between T2 and T3 versions of this three-item scale was appreciably high, $r_{x y}=.629$. Considering replicable evidence for (a) a consistent subset of three items, with (b) high reliability, and (c) consistent factor structures, we are comfortable using this shortened three-item scale in our analyses. Summaries of item reduction analyses are available in our online appendix. Moreover, the online appendix includes results of a supplemental analysis with the full 7-item experienced incivility scale. In summary, parameter estimates were by-and-large the same in terms of the substantive conclusions.

Job Satisfaction. Job satisfaction was assessed with a reliable, well-validated, and widely-used single item at T2 and T3 (Dolbier et al., 2005; Wanous et al., 1997): "All in all, how satisfied have you been with your job in the past month (i.e., the last 4 weeks)?" Participants responded on a 5-point scale ranging from 1 (very dissatisfied) to 5 (very satisfied). Single-item measures of job satisfaction have been shown to have high reliability, as estimated based on the correction for attenuation formula and a factor analysis/communality approach (i.e., in studies that assessed job satisfaction using both a single-item measure and a multi-item scale; Wanous et 
al., 1997; Wanous \& Hudy, 2001). In addition, research has demonstrated that a single-item measure of job satisfaction has adequate test-retest reliability $(r=.70$ across a 1-month time lag, $r=.60$ across a 3-month time lag; Fisher et al., 2016). In support of construct validity, job satisfaction was positively related to a measure of emotional job engagement (Rich et al., 2010) at T2 and T3 of our study (range of $r_{x y}=.42-.61$, all $p s<.05$ ). Emotional job engagement is a motivational construct that entails employees' level of positive affective energy in the work role (Kahn, 1990). Supplemental analyses (see online appendix) showed that including emotional engagement instead of job satisfaction in our analyses yielded a similar pattern of results.

Emotional Exhaustion. We used the four highest loading items from the 9-item emotional exhaustion scale by Maslach and Jackson (1981) to measure emotional exhaustion at T2 and T3, again referring to the past month. The items were, "I felt burned out from my work," "I felt emotionally drained from my work," "I felt used up at the end of the workday," and "I felt fatigued when I got up in the morning and had to face another day on the job." Responses were provided on a 1 (never) to 5 (always) scale. This measure demonstrated good reliability at T2 ( $\alpha$ $=.934, \omega=.934, \mathrm{AVE}=.781)$ and T3 $(\alpha=.940, \omega=.940, \mathrm{AVE}=.796)$. In the validation study, the shortened 4-item scale $(M=2.63, S D=1.09)$ was highly correlated $(r=.95, p<.001)$ with the full 9-item scale $(M=2.49, S D=.99)$. This measure exhibited strong measurement invariance between T2 and T3 (see online appendix).

Demographic, Employment, and Control Variables. At T1, participants self-reported their chronological age in years since birth. As research suggests that occupational well-being may differ based on employee sex (Moen \& Spencer, 2006), educational level (Witter et al., 1984), and income (Judge et al., 2010), we controlled for T1 sex (1 = male, 2 =female $)$, education $(1$ = primary school, $5=$ [technical $]$ college/university $)$, and monthly household 
income (in Euros) in an additional analysis. Moreover, the SAVI model offers that age-related changes in experience and future time perspective predict emotion regulation (Charles, 2010). Accordingly, we also controlled for T1 professional experience (in years) and the 3-item "perceived remaining time" scale from a measure of occupational future time perspective (Zacher \& Frese, 2009). An example item for the latter is "Most of my occupational life lies ahead of me" $(1=$ not true at all to 5 completely true; $\alpha=.650, \omega=.641, \mathrm{AVE}=.599)$. Finally, we assessed the industry participants were working in using 21 categories (e.g., construction, human health and social work activities, information and communication, manufacturing, wholesale and retail trade) based on the Statistical Classification of Economic Activities in the European Community (Eurostat, 2008). A series of linear models accounting for familywise error rates showed that there were no statistically significant industry-to-industry differences observed for any of our focal variables $\left(\mathrm{R}^{2}\right.$ adjusted ranged from $<.001$ to .017 , average $\mathrm{R}_{\text {adjusted }}=$ .002 ; see online appendix for complete results). Therefore, we decided to not include dummycoded variables for industry as covariates in our model and instead used this variable for descriptive purposes only (see section on participants and procedure).

\section{Statistical Analyses}

We initially ran confirmatory factor analyses (CFA) to support measurement model fits. The focal model depicted in Figure 1 was tested using structural equation modeling. To specify latent variable interactions, we used the product indicator approach (Cortina et al., 2021; Marsh et al., 2004). T2-T3 changes in job satisfaction and emotional exhaustion were specified as latent change scores (McArdle, 2001). All analyses presented below were conducted in R using `lavaa` (Rosseel, 2012) with a maximum likelihood estimator.

\section{Results}


Descriptive statistics and correlations among study variables can be found in Table 2. We first conducted a CFA to demonstrate the factor structure of the substantive variables. We specified a five-factor CFA (i.e., defining unique factors for T1 emotion regulation, T1 physiological disease, T2 experienced incivility, T3 job satisfaction, specified as a single-item, and T3 emotional exhaustion), and compared the fit of this model to a one-factor model (i.e., representing these six variables as a single factor). The fit of the five-factor model $\left(\chi^{2}[68]=\right.$ $133.595, p<.001, \mathrm{CFI}=.988, \mathrm{RMSEA}=.035, \mathrm{SRMR}=.027)$ was superior to the fit of the onefactor model $\left(\chi^{2}[79]=5,230.510, p<.001, \mathrm{CFI}=.059, \mathrm{RMSEA}=.289, \mathrm{SRMR}=.336 ; \Delta \chi^{2}[11]=\right.$ $5,230.915, p<.001)$.

To test our hypotheses, we specified a structural equation model (i.e., measurement + structural model). Figure 1 provides a conceptual representation of this model; results of relevant parameter estimates can be found in Table 3. Specifically, building upon the five-factor CFA model (i.e., the measurement model), we regressed the latent variables representing T1 emotion regulation and $\mathrm{T} 1$ physiological disease (i.e., the "a-paths" of our mediation model) onto T1 employee age. We likewise regressed latent change scores representing T2-T3 change in job satisfaction and T2-T3 change in emotional exhaustion onto emotion regulation, physiological disease (i.e., the unconditional "b-paths" of our mediation model), and onto the latent interactions between $\mathrm{T} 2$ experienced incivility and $\mathrm{T} 1$ emotion regulation and $\mathrm{T} 1$ physiological disease (i.e., the conditional "b-paths" of our mediation model), as well as T1 age (i.e., the direct effects or " $c$ '-paths" of our mediation model; see Figure 1). This model fit the data well $\left(\chi^{2}\right.$ [273] $=$ 655.084, $p<.001, \mathrm{CFI}=.962, \mathrm{RMSEA}=.042, \mathrm{SRMR}=.067)$.

Regarding the "a-path" relationships, we observed a positive association between age and emotion regulation $(B=.011, p<.001)$, and a positive relationship between age and 
physiological disease $(B=.008, p<.001)$, suggesting that older as compared to younger age was associated with higher levels of emotion regulation and more diagnosed health symptoms, respectively. Regarding unconditional "b-path" relationships, higher emotion regulation was associated with increases in job satisfaction $(B=.163, p=.003)$ and with decreases in emotional exhaustion $(B=-.195, p<.001)$ from T2 to T3. In contrast, higher physiological disease was associated with decreases in job satisfaction $(B=-.656, p=.027)$ and increases in emotional exhaustion $(B=.606, p=.026)$ from T2 to T3. The direct effect of age on T2-T3 change in job satisfaction was positive $(B=.009, p=.019)$, whereas the direct effect of age on T2-T3 change in emotional exhaustion was negative $(B=-.009, p=.013)$.

Combining "a-path" and "b-path" relationships leads to tests of (unconditional) indirect effects. Given that the sampling distribution of indirect effects (" $a b$ ") is known to be non-normal, we used the Monte Carlo method (based upon 10,000 random draws) to estimate asymptoticallyappropriate percentile-based confidence intervals for these effects (see Preacher \& Selig, 2012). The indirect effect of age on T2-T3 change in job satisfaction through emotion regulation was positive $\left(B_{a b}=.002,95 \%\right.$ CI: $\left.[.001 ; .003]\right)$, whereas the indirect effect of age on T2-T3 change in emotional exhaustion through emotion regulation was negative $\left(B_{a b}=-.002,95 \% \mathrm{CI}[-.04\right.$; $.001])$. Moreover, the indirect effect of age on T2-T3 change in job satisfaction through physiological disease was negative $\left(B_{a b}=-.005,95 \%\right.$ CI $\left.[-.010 ;-.001]\right)$, whereas the indirect effect of age on T2-T3 change in emotional exhaustion through physiological disease was positive $\left(B_{a b}=.005,95 \%\right.$ CI $\left.[.006 ; .010]\right)$.

Our hypotheses suggest that experienced incivility moderates the indirect effects of age on (a) T2-T3 change in job satisfaction through emotion regulation (Hypothesis 1), (b) T2-T3 change in emotional exhaustion through emotion regulation (Hypothesis 2), (c) T2-T3 change in 
job satisfaction through physiological disease (Hypothesis 3), and (d) T2-T3 change in emotional exhaustion through physiological disease (Hypothesis 4; see Figure 1). Regarding conditional "bpath" relationships, we observed only a significant interaction of $\mathrm{T} 1$ emotion regulation and $\mathrm{T} 2$ experienced incivility on T2-T3 change in emotional exhaustion $(B=.154, p=.017)$. To understand the nature of this interaction, we computed estimates of simple slopes. When experienced incivility was high (i.e., $+1 S D$ above the mean), the relationship between emotion regulation and T2-T3 change in emotional exhaustion was non-significant $\left(B_{\text {simple high }}=-.041, \mathrm{SE}\right.$ $=.082, p=.614)$; however, when experienced incivility was low (i.e., $-1 S D$ below the mean) the relationship between emotion regulation and T2-T3 change in emotional exhaustion was significant and negative $\left(B_{\text {simple low }}=-.349, \mathrm{SE}=.082, p<.001\right)$. Thus, higher emotion regulation is only associated with T2-T3 decreases in emotional exhaustion when experienced incivility is low (see Figure 2). We did not find significant interaction effects of experienced incivility and emotion regulation on $\mathrm{T} 2-\mathrm{T} 3$ change in job satisfaction or of experienced incivility and physiological disease on T2-T3 changes in job satisfaction and emotional exhaustion (Table 3). Following from the "a-path" and conditional "b-path" relationships noted, we next considered the conditional indirect effects of T1 age on T2-T3 change in emotional exhaustion through T1 emotion regulation, conditional upon T2 experienced incivility. As with unconditional indirect effects, we used the Monte Carlo method (based upon 10,000 random draws) to estimate asymptotically appropriate percentile-based confidence intervals for conditional indirect effects. Consistent with the pattern of simple slopes described above, when experienced incivility was high (i.e., $+1 S D$ above the mean), the indirect effect of age on change in emotional exhaustion through emotion regulation was non-significant $\left(B_{a b}\right.$ low $=<-.001,95 \%$ CI $[-.002 ; .001])$. When experienced incivility was low (i.e., $-1 S D$ below the mean), the indirect 
effect of age on change emotional exhaustion through emotion regulation was significant and negative $\left(B_{a b}\right.$ high $=-.004,95 \%$ CI $\left.[-.067 ;-.002]\right)$. Corroborating and qualifying the direct effect described above, this finding suggests that higher (vs. lower) age is related to decreases in emotional exhaustion through emotion regulation, and that this effect is stronger when experienced incivility is low (vs. high). Overall, these findings provide support for Hypothesis 1, but no support for Hypotheses 2-4. Thus, although we did find that emotion regulation and physiological disease mediated the relationships between age and changes in both well-being outcomes, these effects were not observed to be conditional upon experienced incivility.

In terms of variance explained, $R^{2}=.033(3.30 \%)$ of the variance in T1 emotion regulation and $R^{2}=.232(23.63 \%)$ of the variance in T1 physiological disease was explained by age. Moreover, $R^{2}=.319(31.90 \%)$ of the variance in T2-T3 change in job satisfaction and $R^{2}=$ $.264(26.40 \%)$ of the variance in T2-T3 change in emotional exhaustion was explained by age, emotion regulation, and physiological disease, as well as the interactions between experienced incivility and emotion regulation and physiological disease. Finally, regarding the variance explained by the specific theoretical pathways embodied in our model (i.e., the strength pathway through emotion regulation vs. the vulnerability pathway through physiological disease), $R^{2}=$ $.307(30.70 \%)$ of the variance in T2-T3 change in job satisfaction and $R^{2}=.243(24.26 \%)$ of the variance in T2-T3 change in emotional exhaustion occurred through the strength pathway (i.e., observed when fixing parameters in the vulnerability pathway to zero), whereas $R^{2}=.298$ $(29.78 \%)$ of the variance in T2-T3 change in job satisfaction and $R^{2}=.219(21.98 \%)$ of the variance in T2-T3 change in emotional exhaustion occurred through the vulnerability pathway (i.e., observed when fixing parameters in the strength pathway to zero).

\section{Sensitivity Analyses}


We conducted a sensitivity analysis wherein we re-specified our focal model with the inclusion of T1 sex, education, income, professional experience, and perceived remaining time. In summary of this analysis, we observed that model fit decreased in comparison to the focal model presented above when specifying these covariates $\left(\chi^{2}[349]=807.517, p<.001, \mathrm{CFI}=.954\right.$, $\left.\mathrm{RMSEA}=.042, \mathrm{SRMR}=.073 ; \Delta \chi^{2}{ }_{[76]}=151.713, p<.001\right)$. Moreover, in this model, parameter estimates were by-and-large the same in terms of the substantive conclusions drawn regarding such estimates, in particular regarding the moderating effects of experienced incivility. Full results are available in our online appendix.

\section{Discussion}

Lifespan theories are frequently used to explain relationships between employee age and occupational well-being (Rudolph, 2016; Zacher, 2020). However, compared to socioemotional selectivity theory (Carstensen, 1995), which focuses on future time perspective as the central mechanism of these associations, the SAVI model (Charles, 2010) has received much less attention by organizational researchers. A few studies have used this model as a framework to examine direct and interactive effects of age and work-related stressors (i.e., customer mistreatment, age discrimination, emotional job demands), but the two divergent age-related mechanisms proposed by the model—emotion regulation and physiological flexibility—were not operationalized (Amarnani et al., 2019; Marchiondo et al., 2019; Reh et al., 2021). To advance this literature, the present study drew on the SAVI model to develop and test a conceptual model on indirect effects of age on changes in job satisfaction and emotional exhaustion via emotion regulation (i.e., strength pathway) and physiological disease (i.e., vulnerability pathway), conditional upon the level of incivility employees experience at their workplace.

Results showed that age had unconditional indirect effects (i.e., independent of 
experienced incivility) on changes in job satisfaction and emotional exhaustion through emotion regulation and physiological disease. Specifically, consistent with expectations based on the SAVI model, age was positively related to both emotion regulation and physiological disease, suggesting that older employees are generally better at regulating their emotions, but are also more likely to experience physiological health problems than younger employees. We further found that, independent of experienced incivility, higher emotion regulation was related to increases in job satisfaction and decreases in emotional exhaustion, whereas higher physiological disease was related to decreases in job satisfaction and increases in emotional exhaustion. These findings were unexpected because, based on the SAVI model, we hypothesized that emotion regulation only impacts occupational well-being when experienced incivility is low (vs. high), whereas physiological disease should only affect well-being when incivility is high (vs. low).

Only one of our four hypotheses on conditional indirect effects of age on changes in occupational well-being outcomes was supported. Specifically, high levels of experienced incivility weakened the effect of higher age on decreases in emotional exhaustion through emotion regulation. Consistent with the SAVI model, this finding suggests that age-related strengths in emotion regulation are more effective in terms of reducing emotional exhaustion when employees experience low incivility, whereas emotion regulation is less effective when employees experience high levels of this workplace stressor. In contrast, we did not find support for the hypothesized moderating effects of experienced uncivility on the effects of emotion regulation and physiological disease on changes in job satisfaction, and on the effect of physiological disease on changes in emotional exhaustion. Future research could examine whether the "triple match principle" from the occupational health psychology literature might also apply to relationships among age-related characteristics, workplace stressors, and 
occupational well-being outcomes, or could even be integrated with propositions of the SAVI model. According to this principle, job stressors and resources are most likely to have interactive effects on occupational well-being when stressors, resources, and outcomes match in terms of their focus (de Jonge \& Dormann, 2006). For instance, emotion-related job resources should be most likely to buffer the effects of emotional job stressors on emotional well-being. Although there appears to be a match between emotion regulation, incivility as a socioemotional stressor, and emotional exhaustion, the focus of physiological disease and incivility is different.

Consistent with theorizing on emotional aging (Scheibe \& Zacher, 2013) and the results of a meta-analysis ( $\mathrm{Ng} \&$ Feldman, 2010), bivariate correlations showed that age was positively related to job satisfaction and negatively related to emotional exhaustion, suggesting that older employees feel generally more satisfied with and less exhausted due to their work than younger employees. As noted above, these associations can be partially explained by older employees' higher levels of both emotion regulation and physiological disease. Interestingly, additional analyses showed that the strength pathway and the vulnerability pathway accounted for similar proportions of the variance in changes in occupational well-being outcomes when the parameters in the respective other pathway were fixed to zero. Nevertheless, given the positive overall relationship between age and job satisfaction and the negative overall relationship between age and emotional exhaustion, it appears that all of the potential age-related strengths underlying these associations are more dominant than all of the potential underlying vulnerabilities.

We further found negative associations between age and experienced incivility at T2 ( $r=$ $-.23, p<.001)$ and T3 $(r=-.29, p<.001$; see Table 2$)$ in our study, suggesting that older employees generally experience lower levels of incivility shown by their supervisors and coworkers than younger employees. This finding is consistent with a recent meta-analysis that, 
based on 103 independent samples, reported an average relationship of $\rho=-.18$ between employee age and customer mistreatment (Okan et al., 2021). These associations can be explained in part by the social input model (Fingerman \& Charles, 2010), which offers that older adults act in ways to make their social environments more benign, and that older adults' social partners are motivated to treat them more kindly (e.g., to avoid conflict). Similarly, theorizing on age and occupational well-being suggests that aging is not only associated with changes in life contexts (e.g., shifts in work and family demands and roles), but also with changes in attention to and appraisal of affective work events (Scheibe \& Zacher, 2013). Thus, older employees may experience less incivility because (a) other people actually show such behaviors less frequently in older employees' work environment, (b) older employees are better at avoiding others who show these behaviors, or (c) that they interpret others' incivility differently than younger employees. Another possible explanation for the negative association between age and experienced incivility may be that the cohort of older workers in our study were working in jobs in which their age-related strengths were valued (e.g., "knowledge workers"). In contrast, older workers in jobs requiring higher levels of physical strength or cognitive processing speed (i.e., which generally constitute age-related vulnerabilities) may have been less represented in our sample. We conducted an analysis to explore this potential explanation and did not find systematic age differences between participants' industry (see online appendix for full results).

\section{Theoretical and Practical Implications}

The results of this study contribute to theory development in the areas of age and work, occupational well-being, and workplace incivility. First, investigating our conceptual model based on the SAVI model in an employee sample contributes to a better understanding of the simultaneous occurrence of age-related gains (or strengths) and losses (or vulnerabilities) in the 
work context. While research has acknowledged that there is much heterogeneity within the groups of younger and older employees, there seem to be also systematic, albeit relatively weak, age-related differences (Bohlmann et al., 2018). Emotion regulation has been noted as an agerelated strength of older employees in the literature (Doerwald et al., 2016; Johnson et al., 2013), which generally has focused more on the opportunities than on the risks of older employee age (see Hertel \& Zacher, 2018). Indeed, age-related losses, such as a higher likelihood of physiological disease among older employees, have not been systematically integrated in conceptual models of age and work. Thus, a theoretical contribution of our study is that it, consistent with the lifespan perspective (Baltes, 1987), highlights the importance of considering both age-related gains and losses, as well as their implications for occupational well-being.

Second, our findings advance the occupational health psychology literature by showing that employee age, age-related characteristics, as well as the interaction between emotion regulation and experienced incivility may impact occupational well-being. Numerous studies and two meta-analyses have reported bivariate, generally rather weak associations between age and various well-being outcomes, including job satisfaction and emotional exhaustion $(\mathrm{Ng} \&$ Feldman, 2010). However, the underlying age-related mechanisms of these associations are rarely investigated (Bohlmann et al., 2018). Based on the SAVI model, this study demonstrated that two individual characteristics represent divergent pathways leading from age to occupational well-being. Future theory development could integrate these age-related individual mechanisms with age-related contextual mechanisms, such as work and family demands (Scheibe \& Zacher, 2013), as well as employees' and their social partners' actions (Fingerman \& Charles, 2010), which may also impact occupational well-being. For instance, based on role theory, a study found that age has indirect effects on job satisfaction and emotional exhaustion via time pressure 
and coworker support, with higher time pressure and lower coworker support among employees in mid-career as compared to relatively younger and older employees (Zacher et al., 2014).

Third, our findings contribute to theorizing on workplace incivility, which has so far neglected interactive effects with age-related characteristics on occupational well-being (Schilpzand et al., 2016). Consistent with much previous research (e.g., Cortina et al., 2001), we replicated detrimental effects of experienced incivility on occupational well-being in this study (i.e., negative associations with job satisfaction and positive associations with emotional exhaustion; see Table 2). More interestingly, we found that age only had a negative indirect effect on emotional exhaustion through emotion regulation when experienced incivility was low (vs. high). Accordingly, future theory development could focus on workplace incivility as a barrier to the utilization of age-related strengths to maintain occupational well-being.

Due to our observational study design, we cannot draw definite conclusions regarding causality. Accordingly, we offer only tentative practical recommendations based on our findings. Our results showed that individual differences in emotion regulation and physiological disease were associated with subsequent changes in occupational well-being across three months. Thus, employees with greater emotion regulation skills and better physical health may be more likely to report increases in job satisfaction and decreases in emotional exhaustion across such time spans. These occupational well-being outcomes have been linked to higher general well-being, job performance, and lower turnover (Hakanen \& Schaufeli, 2012; Judge \& Watanabe, 1993; Wright \& Cropanzano, 1998). Organizational practitioners might be able to increase employee well-being by helping employees develop such skills. Indeed, research suggests that the effective use of emotion regulation can be trained (e.g., Cohen \& Ochsner, 2018). Practitioners could also take active steps to prevent the emergence of physiological diseases across the working lifespan, 
for instance through work design (Parker, 2014) or by affording high-quality healthcare benefits to employees that mitigate the development of such disease in the first place. Finally, given significant associations between experienced incivility and occupational well-being outcomes in this study, employees might benefit when their organization implements policies and practices that reduce the enactment of incivility by supervisors and coworkers (Hodgins et al., 2014).

\section{Limitations and Future Research}

This study has several limitations that should be addressed in future research. First, two central limitations of our study are that we (a) did not measure all constructs at all three time points and (b) focused on changes in occupational well-being outcomes across a relatively short time period (i.e., three months between T2 and T3). Accordingly, our study design does not allow drawing conclusions about (reverse) causality, reciprocal effects, and longer term developmental changes (i.e., aging). Consistent with other recent studies (e.g., Gielnik et al., 2018; Wang et al., 2015), we assessed age and age-related mechanisms at the same time point, because age is an exogenous variable that cannot be influenced by emotion regulation and physiological disease. However, our design does not allow us to test reciprocal effects among emotion regulation, physiological disease, and occupational well-being. For instance, while certain physiological diseases may make it more difficult to regulate emotions effectively, particularly when experiencing high levels of stress (Charles, 2010), research also suggests that poor emotion regulation (i.e., greater emotional reactivity to daily stressors) is associated with increased risk of developing a chronic physical health condition (Piazza et al., 2013) and even mortality (Mroczek et al., 2015) across ten years. Moreover, a meta-analysis found positive effects of well-being on favorable short- and long-term health outcomes; interestingly, however, there were no significant effects of well-being on cardiovascular and physiological reactivity (R. 
T. Howell et al., 2007). The SAVI model focuses on the process of aging, whereas our study is only able to examine interindividual differences in age, emotion regulation, and physiological disease as predictors of short-term changes in occupational well-being. Further longitudinal and experimental research based on the SAVI model is needed to better establish the flow of causality among age-related strengths and vulnerabilities of older workers and their well-being.

Second, our survey measures of individual differences in emotion regulation and physiological disease constitute only proxies of the use of attentional, appraisal, and behavioral emotion regulation strategies and the process of physiological flexibility proposed by the SAVI model, respectively (Charles, 2010). Moreover, we included experience and future time perspective only as control variables and not a-priori as mechanisms of the association between age and emotion regulation in our conceptual model. While research has demonstrated that age is related to experience and future time perspective in the work context (Gielnik et al., 2018), and that experience and future time perspective, in turn, are associated with emotion regulation (Grant, 2013; Yeung et al., 2020), future research should examine a multi-stage mediation model including indirect effects of age on occupational well-being outcomes through (a) experience and future time perspective and (b) emotion regulation, conditional upon the level of work stressors.

Third, all measures in our study were collected via self-reports, which is not ideal. Although our time-lagged design should partially assuage concerns about method variance inflating our parameter estimates (e.g., Podsakoff et al., 2012), future research should consider the convergence of self-reports and other sources of data (e.g., peer-reports of workplace incivility; medical conditions objectively coded from health records).

Fourth, we observed low reliability for our measure of physiological disease. Although this is not surprising for such a diagnostic index, future research should extend the measurement 
of physiological disease beyond diagnosed status to consider ancillary measures of symptom severity and daily impairments. Moreover, it is important to acknowledge that age-related physiological diseases are heterogeneous in their etiology and manifestation and may have different effects on occupational well-being because they elicit different forms of stress reactivity (e.g., owing to differences in symptom severity, regardless of diagnosed status). Our measure of a narrow range of diagnosed age-related physiological diseases is too coarse to parse potential differential reactivity, and future research should address this by considering a broader range of age-related diseases in terms of their diagnosed status and in terms of specific symptomology and the manifestation and severity thereof, over time. Still, given the age-graded nature of these diseases (see correlations reported above, and in the online appendix), and our findings regarding their association with changes in employee wellbeing, we contend that they are a reasonable proxy of age-related physiological disease in the present study.

Finally, we focused only on one workplace stressor (i.e., experienced incivility). As such, we do not know how generalizable our findings are to other work-related stressors, especially those that are more intense (e.g., bullying). Related to this last point, we also observed low average levels of experienced incivility (i.e., $M=1.60$ on a 5-point scale) and physiological disease $(M=0.64$ diagnosed symptoms on a 4-point scale ranging from 0 to 3 ), which might suggest that there are base rate concerns (e.g., "floor effects") at play here. Empirical support for the hypothesized interaction effects based on the SAVI model may be more likely in employee samples that report higher mean levels and greater variation in experienced incivility and physiological disease (e.g., relatively older customer service employees or blue-collar workers). Furthermore, these interaction effects may be more likely to emerge for workplace stressors that are less severe, but more commonly experienced at work than incivility (e.g., daily hassles, time 
pressure, interruptions), or for measures of momentary symptom severity of various age-related physiological diseases (e.g., transient experiences of breathing difficulties, heart racing, dizziness, fatigue).

Future research could examine the moderating effects of workplace stressors that have a stronger conceptual link with age, such as experiences of age discrimination or age-related stereotype threat (i.e., the concern that one is being discriminated against based on one's age; Von Hippel et al., 2019). More generally, we suggest that future empirical research in the work context based on the SAVI model clearly explains how it operationalizes the model's core constructs (e.g., emotional well-being as an outcome) and tests its core propositions (e.g., agerelated mechanisms, stressful experiences as moderators).

\section{Conclusion}

Drawing on the SAVI model from the lifespan literature, we developed and tested a conceptual model on experienced incivility as a moderator of the indirect effects of employee age on changes in job satisfaction and emotional exhaustion through emotion regulation and physiological disease. We found indirect effects of age on occupational well-being outcomes through emotion regulation and physiological disease, independent of experienced civility. However, only one of our four conditional indirect effect hypotheses based on the SAVI model was supported: the indirect effect of higher (vs. lower) age on decreases in emotional exhaustion through emotion regulation was weaker and non-significant when experienced incivility was high (vs. low). We hope that these findings have bearing on the application of lifespan theories and future empirical studies in the work context, and that they inspire organizational practitioners to focus on ways to improve occupational well-being across the lifespan. 


\section{References}

Amarnani, R. K., Restubog, S. L. D., Bordia, P., \& Abbasi, A. A. (2019). Age as double-edged sword among victims of customer mistreatment: A self-esteem threat perspective. Human Resource Management, 58(3), 285-299. https://doi.org/10.1002/hrm.21949

Baltes, P. B. (1987). Theoretical propositions of life-span developmental psychology: On the dynamics between growth and decline. Developmental Psychology, 23(5), 611-626. https://doi.org/10.1037/0012-1649.23.5.611

Blanchard-Fields, F. (2007). Everyday problem solving and emotion: An adult developmental perspective. Current Directions in Psychological Science, 16(1), 26-31. https://doi.org/10.1111/j.1467-8721.2007.00469.x

Blau, G., \& Andersson, L. (2005). Testing a measure of instigated workplace incivility. Journal of Occupational and Organizational Psychology, 78(4), 595-614. https://doi.org/10.1348/096317905X26822

Bohlmann, C., Rudolph, C. W., \& Zacher, H. (2018). Methodological recommendations to move research on work and aging forward. Work, Aging and Retirement, 4(3), 225-237. https://doi.org/10.1093/workar/wax023

Brief, A. P., \& Weiss, H. M. (2002). Organizational behavior: Affect in the workplace. Annual Review of Psychology, 53, 279-307. https://doi.org/10.1146/annurev.psych.53.100901

Buruck, G., Dörfel, D., Kugler, J., \& Brom, S. S. (2016). Enhancing well-being at work: The role of emotion regulation skills as personal resources. Journal of Occupational Health Psychology, 21(4), 480-493. https://doi.org/10.1037/ocp0000023

Carstensen, L. L. (1995). Evidence for a life-span theory of socioemotional selectivity. Current Directions in Psychological Science, 4, 151-156. https://doi.org/10.1111/1467- 


\section{$\underline{8721 . e p 11512261}$}

Carstensen, L. L., Fung, H. H., \& Charles, S. T. (2003). Socioemotional selectivity theory and the regulation of emotion in the second half of life. Motivation and Emotion, 27, 103-123. https://doi.org/10.1023/A:1024569803230

Charles, S. T. (2010). Strength and vulnerability integration: A model of emotional well-being across adulthood. Psychological Bulletin, 136(6), 1068-1091. https://doi.org/10.1037/a0021232

Charles, S. T., \& Carstensen, L. L. (2010). Social and emotional aging. Annual Review of Psychology, 61, 383-409. https://doi.org/10.1146/annurev.psych.093008.100448

Charles, S. T., \& Luong, G. (2013). Emotional experience across adulthood: The theoretical model of strength and vulnerability integration. Current Directions in Psychological Science, 22(6), 443-448. https://doi.org/10.1177/0963721413497013

Charles, S. T., Piazza, J. R., Luong, G., \& Almeida, D. M. (2009). Now you see it, now you don't: Age differences in affective reactivity to social tensions. Psychology and Aging, 24(3), 645-653. https://doi.org/10.1037/a0016673

Cohen, J. (1988). Statistical power analysis for the behavioral sciences. Lawrence Erlbaum.

Cohen, N., \& Ochsner, K. N. (2018). From surviving to thriving in the face of threats: the emerging science of emotion regulation training. Current Opinion in Behavioral Sciences, 24, 143-155. https://doi.org/10.1016/j.cobeha.2018.08.007

Cortina, J. M., Markell-Goldstein, H. M., Green, J. P., \& Chang, Y. (2021). How are we testing interactions in latent variable models? Surging forward or fighting shy? Organizational Research Methods, 24(1), 26-54. https://doi.org/10.1177/1094428119872531

Cortina, J. M., Sheng, Z., Keener, S. K., Keeler, K. R., Grubb, L. K., Schmitt, N., Tonidandel, S., 
Summerville, K. M., Heggestad, E. D., \& Banks, G. C. (2020). From alpha to omega and beyond! A look at the past, present, and (possible) future of psychometric soundness in the Journal of Applied Psychology. Journal of Applied Psychology, 105(12), 1351-1381. https://doi.org/10.1037/ap10000815

Cortina, L. M., Magley, V. J., Williams, J. H., \& Langhout, R. D. (2001). Incivility in the workplace: Incidence and impact. Journal of Occupational Health Psychology, 6(1), 6480. https://doi.org/10.1037//1076-8998.6.1.64

de Jonge, J., \& Dormann, C. (2006). Stressors, resources, and strain at work: A longitudinal test of the triple-match principle. Journal of Applied Psychology, 91(5), 1359-1374. https://doi.org/10.1037/0021-9010.91.5.1359

De Zwart, B. C. H., Frings-Dresen, M. H. W., \& Van Duivenbooden, J. C. (2002). Test-retest reliability of the Work Ability Index questionnaire. Occupational Medicine, 52(4), 177 181. https://doi.org/10.1093/occmed/52.4.177

Diamantopoulos, A., Riefler, P., \& Roth, K. P. (2008). Advancing formative measurement models. Journal of Business Research, 61(12), 1203-1218. https://doi.org/10.1016/j.jbusres.2008.01.009

Doerwald, F., Scheibe, S., Zacher, H., \& Van Yperen, N. W. (2016). Emotional competencies across adulthood: State of knowledge and implications for the work context. Work, Aging and Retirement, 2(2), 159-216. https://doi.org/10.1093/workar/waw013

Dolbier, C. L., Webster, J. A., McCalister, K. T., Mallon, M. W., \& Steinhardt, M. A. (2005). Reliability and validity of a single-item measure of job satisfaction. American Journal of Health Promotion, 19(3), 194-198. https://doi.org/10.4278/0890-1171-19.3.194

Eurostat. (2008). NACE Rev. 2: Statistical Classification of Economic Activities in the European 
Community. European Commission.

https://ec.europa.eu/eurostat/documents/3859598/5902521/KS-RA-07-015-EN.PDF

Fingerman, K. L., \& Charles, S. T. (2010). It takes two to tango: Why older people have the best relationships. Current Directions in Psychological Science, 19(3), 172-176. https://doi.org/10.1177/0963721410370297

Fisher, G. G., Matthews, R. A., \& Gibbons, A. M. (2016). Developing and investigating the use of single-item measures in organizational research. Journal of Occupational Health Psychology, 21(1), 3-23. https://doi.org/10.1037/a0039139

Forcier, K., Stroud, L. R., Papandonatos, G. D., Hitsman, B., Reiches, M., Krishnamoorthy, J., \& Niaura, R. (2006). Links between physical fitness and cardiovascular reactivity and recovery to psychological stressors: A meta-analysis. Health Psychology, 25(6), 723739. https://doi.org/10.1037/0278-6133.25.6.723

Gielnik, M. M., Zacher, H., \& Wang, M. (2018). Age in the entrepreneurial process: The role of future time perspective and prior entrepreneurial experience. Journal of Applied Psychology, 103(10), 1067-1085. https://doi.org/10.1037/ap10000322

Grant, A. M. (2013). Rocking the boat but keeping it steady: The role of emotion regulation in employee voice. Academy of Management Journal, 56(6), 1703-1723. https://doi.org/10.5465/amj.2011.0035

Hakanen, J. J., \& Schaufeli, W. B. (2012). Do burnout and work engagement predict depressive symptoms and life satisfaction? A three-wave seven-year prospective study. Journal of Affective Disorder, 141(2), 415-424. https://doi.org/10.1016/j.jad.2012.02.043

Hertel, G., \& Zacher, H. (2018). Managing the aging workforce. In D. S. Ones, N. Anderson, C. Viswesvaran, \& H. K. Sinangil (Eds.), The Sage handbook of industrial, work and 
organizational psychology (2nd ed., Vol. 3, pp. 396-428). Sage.

Hodgins, M., MacCurtain, S., \& Mannix-McNamara, P. (2014). Workplace bullying and incivility: A systematic review of interventions. International Journal of Workplace Health Management, 7(1), 54-72. https://doi.org/10.1108/IJWHM-08-2013-0030

Howell, R. D., Breivik, E., \& Wilcox, J. B. (2007). Reconsidering formative measurement. Psychological Methods, 12(2), 205-218. https://doi.org/10.1037/1082-989X.12.2.205

Howell, R. T., Kern, M. L., \& Lyubomirsky, S. (2007). Health benefits: Meta-analytically determining the impact of well-being on objective health outcomes. Health Psychology Review, 1(1), 83-136. https://doi.org/10.1080/17437190701492486

Ilmarinen, J., Tuomi, K., \& Klockars, M. (1997). Changes in the work ability of active employees over an 11-year period. Scandinavian journal of work, environment \& health, 23(1), 49-57. https://doi.org/http://www.jstor.org/stable/40966691

Jiang, D., \& Fung, H. H. (2019). Social and emotional theories of aging. In B. B. Baltes, C. W. Rudolph, \& H. Zacher (Eds.), Work across the lifespan (pp. 135-153). Academic Press.

Johnson, S. J., Holdsworth, L., Hoel, H., \& Zapf, D. (2013). Customer stressors in service organizations: The impact of age on stress management and burnout. European Journal of Work and Organizational Psychology, 22(3), 318-330. https://doi.org/10.1080/1359432X.2013.772581

Judge, T., \& Watanabe, S. (1993). Another look at the job satisfaction-life satisfaction relationship. Journal of Applied Psychology, 78, 939-948. 10.1037/0021-9010.78.6.939

Judge, T. A., Piccolo, R. F., Podsakoff, N. P., Shaw, J. C., \& Rich, B. L. (2010). The relationship between pay and job satisfaction: A meta-analysis of the literature. Journal of Vocational Behavior, 77(2), 157-167. https://doi.org/10.1016/j.jvb.2010.04.002 
Kahn, W. A. (1990). Psychological conditions of personal engagement and disengagement at work. Academy of Management Journal, 33, 692-724. https://doi.org/10.2307/256287

Karunamuni, N., Imayama, I., \& Goonetilleke, D. (2021). Pathways to well-being: Untangling the causal relationships among biopsychosocial variables. Social Science \& Medicine, 272, 112846. https://doi.org/10.1016/j.socscimed.2020.112846

Kooij, D. T. A. M., De Lange, A. H., Jansen, P. G. W., \& Dikkers, J. S. E. (2013). Beyond chronological age: Examining perceived future time and subjective health as age-related mediators in relation to work-related motivations and well-being. Work \& Stress, 27(1), 88-105. https://doi.org/10.1080/02678373.2013.769328

Lawrence, S. A., Troth, A. C., Jordan, P. J., \& Collins, A. L. (2011). A review of emotion regulation and development of a framework for emotion regulation in the workplace. In P. L. Perrewé \& D. C. Ganster (Eds.), Research in occupational stress and well-being (pp. 197-263). Emerald.

Leiter, M. P., Peck, E., \& Gumuchian, S. (2015). Workplace incivility and its implications for well-being. In P. L. Perrewè, J. R. B. Halbesleben, \& C. C. Rosen (Eds.), Research in occupational stress and well-being (pp. 107-135). Emerald.

Locke, E. A. (1976). The nature and causes of job satisfaction. In M. D. Dunnette (Ed.), Handbook of industrial and organizational psychology (pp. 1297-1349). Rand McNally.

Maertens, J. A., Putter, S. E., Chen, P. Y., Diehl, M., \& Huang, Y.-H. (2012). Physical capabilities and occupational health of older workers. In J. W. Hedge \& W. C. Borman (Eds.), The Oxford Handbook of Work and Aging. Oxford University Press. https://doi.org/10.1093/oxfordhb/9780195385052.013.0089

Marchiondo, L. A., Gonzales, E., \& Williams, L. J. (2019). Trajectories of perceived workplace 
age discrimination and long-term associations with mental, self-rated, and occupational health. The Journals of Gerontology: Series B, 74(4), 655-663. https://doi.org/10.1093/geronb/gbx095

Marsh, H. W., Wen, Z., \& Hau, K. T. (2004). Structural equation models of latent interactions: Evaluation of alternative estimation strategies and indicator construction. Psychological Methods, 9(3), 275-300. https://doi.org/10.1037/1082-989X.9.3.275

Maslach, C., \& Jackson, S. E. (1981). The measurement of experienced burnout. Journal of Occupational Behaviour, 2, 99-113. https://doi.org/10.1002/job.4030020205

Maslach, C., Schaufeli, W. B., \& Leiter, M. P. (2001). Job burnout. Annual Review of Psychology, 52(1), 397-422. https://doi.org/10.1146/annurev.psych.52.1.397

McArdle, J. J. (2001). A latent difference score approach to longitudinal dynamic structural analysis. In R. Cudeck, S. du Toit, \& D. Sörbom (Eds.), Structural equation modeling: Present and future (pp. 342-380). Scientific Software International

Moen, P., \& Spencer, D. (2006). Converging divergences in age, gender, health, and well-being: Strategic selection in the third age. In R. H. Binstock, L. K. George, S. J. Cutler, J. Hendricks, \& J. H. Schulz (Eds.), Handbook of aging and the social sciences (pp. 127144). Academic Press.

Mroczek, D. K., Stawski, R. S., Turiano, N. A., Chan, W., Almeida, D. M., Neupert, S. D., \& Spiro III, A. (2015). Emotional reactivity and mortality: Longitudinal findings from the VA Normative Aging Study. Journals of Gerontology Series B: Psychological Sciences and Social Sciences, 70(3), 398-406. https://doi.org/10.1093/geronb/gbt107

Ng, T. W. H., \& Feldman, D. C. (2010). The relationship of age with job attitudes: A metaanalysis. Personnel Psychology, 63, 667-718. 10.1111/j.1744-6570.2010.01184.x 
Ng, T. W. H., \& Feldman, D. C. (2013). Employee age and health. Journal of Vocational Behavior, 83(3), 336-345. https://doi.org/10.1016/j.jvb.2013.06.004

Okan, M., Elmadag, A. B., \& İdemen, E. (2021). Frontline employee age and customer mistreatment: A meta-analysis. Journal of Services Marketing. https://doi.org/10.1108/JSM-06-2019-0246

Parker, S. K. (2014). Beyond motivation: Job and work design for development, health, ambidexterity, and more. Annual Review of Psychology, 65, 661-691. https://doi.org/10.1146/annurev-psych-010213-115208

Pekaar, K. A., Bakker, A. B., van der Linden, D., \& Born, M. P. (2018). Self-and other-focused emotional intelligence: Development and validation of the Rotterdam Emotional Intelligence Scale (REIS). Personality and Individual Differences, 120, 222-233. https://doi.org/10.1016/j.paid.2017.08.045

Piazza, J. R., Charles, S. T., Sliwinski, M. J., Mogle, J., \& Almeida, D. M. (2013). Affective reactivity to daily stressors and long-term risk of reporting a chronic physical health condition. Annals of Behavioral Medicine, 45(1), 110-120. https://doi.org/10.1007/s12160-012-9423-0

Podsakoff, P. M., MacKenzie, S. B., \& Podsakoff, N. P. (2012). Sources of method bias in social science research and recommendation on how to control it. Annual Review of Psychology, 63, 539-569. https://doi.org/10.1146/annurev-psych-120710-100452

Preacher, K. J., \& Selig, J. P. (2012). Advantages of Monte Carlo confidence intervals for indirect effects. Communication Methods and Measures, 6(2), 77-98. https://doi.org/10.1080/19312458.2012.679848

Reh, S., Wieck, C., \& Scheibe, S. (2021). Experience, vulnerability, or overload? Emotional job 
demands as moderator in trajectories of emotional well-being and job satisfaction across the working lifespan. Journal of Applied Psychology. https://doi.org/10.1037/ap10000859

Rich, B. L., LePine, J. A., \& Crawford, E. A. (2010). Job engagement: Antecedents and effects on job performance. Academy of Management Journal, 53(3), 617-635. https://doi.org/10.5465/AMJ.2010.51468988

Rosseel, Y. (2012). lavaan: An R package for structural equation modeling. Journal of Statistical Software, 48(2), 1-36. https://doi.org/10.18637/jss.v048.i02

Rozanski, A., \& Kubzansky, L. D. (2005). Psychologic functioning and physical health: A paradigm of flexibility. Psychosomatic Medicine, 67, S47-S53. https://doi.org/10.1097/01.psy.0000164253.69550.49

Rudolph, C. W. (2016). Lifespan developmental perspectives on working: A literature review of motivational theories. Work, Aging and Retirement, 2, 130-158. https://doi.org/10.1093/workar/waw012

Scheibe, S., \& Carstensen, L. L. (2010). Emotional aging: Recent findings and future trends. The Journals of Gerontology Series B, 65(2), 135-144. https://doi.org/10.1093/geronb/gbp132

Scheibe, S., Yeung, D. Y., \& Doerwald, F. (2019). Age-related differences in levels and dynamics of workplace affect. Psychology and Aging, 34(1), 106-123. https://doi.org/10.1037/pag0000305

Scheibe, S., \& Zacher, H. (2013). A lifespan perspective on emotion regulation, stress, and wellbeing in the workplace. In P. L. Perrewé, J. Halbesleben, \& C. C. Rosen (Eds.), Research in occupational stress and well-being (Vol. 11, pp. 167-197). Emerald. https://doi.org/10.1108/S1479-3555(2013)0000011010

Schilpzand, P., De Pater, I. E., \& Erez, A. (2016). Workplace incivility: A review of the 
literature and agenda for future research. Journal of Organizational Behavior, 37(S1), S57-S88. https://doi.org/10.1002/job.1976

Schmitt, A., \& Bathen, M. (2015). Occupational health, well-being, and aging. In N. A. Pachana (Ed.), Encyclopedia of geropsychology. Springer.

Schmitt, A., Zacher, H., \& Frese, M. (2012). The buffering effect of selection, optimization, and compensation strategy use on the relationship between problem solving demands and occupational well-being: A daily diary study. Journal of Occupational Health Psychology, 17, 139-149. https://doi.org/10.1037/a0027054

Stanton, J. M., Sinar, E. F., Balzer, W. K., \& Smith, P. C. (2002). Issues and strategies for reducing the length of self-report scales. Personnel Psychology, 55(1), 167-194. https://doi.org/10.1111/j.1744-6570.2002.tb00108.x

Tuomi, K., Ilmarinen, J. A., Jahkola, A., Katajarinne, L., \& Tulkki, A. (1998). Work Ability Index (2nd ed.). Finnish Institute of Occupational Health.

Von Hippel, C., Kalokerinos, E. K., Haanterä, K., \& Zacher, H. (2019). Age-based stereotype threat and work outcomes: Stress appraisals and rumination as mediators. Psychology and Aging, 34(1), 68-84. https://doi.org/10.1037/pag0000308

Wang, M., Burlacu, G., Truxillo, D., James, K. S., \& Yao, X. (2015). Age differences in feedback reactions: The roles of employee feedback orientation on social awareness and utility. Journal of Applied Psychology, 100, 1296-1308. https://doi.org/10.1037/a0038334

Wanous, J. P., \& Hudy, M. J. (2001). Single-item reliability: A replication and extension. Organizational Research Methods, 4, 361-375. https://doi.org/10.1177/10944281044003

Wanous, J. P., Reichers, A. E., \& Hudy, M. J. (1997). Overall job satisfaction: How good are single-item measures? Journal of Applied Psychology, 82(2), 247-252. 


\section{https://doi.org/10.1037/0021-9010.82.2.247}

Ware, J. E., Kosinski, M., \& Keller, S. D. (1998). How to Score the SF-12 Physical and Mental Health Summary Scales, 3d. ed. The Health Institute, New England Medical Center.

Weiss, M. \& Zacher, H. (2021, in press). Why and when does voice lead to increased job engagement? The role of perceived voice appreciation and emotional stability. Journal of Vocational Behavior. https://doi.org/10.1016/j.jvb.2021.103662

Witter, R. A., Okun, M. A., Stock, W. A., \& Haring, M. J. (1984). Education and subjective well-being: A meta-analysis. Educational Evaluation and Policy Analysis, 6(2), 165-173. https://doi.org/10.3102/01623737006002165

Wright, T. A., \& Cropanzano, R. (1998). Emotional exhaustion as a predictor of job performance and voluntary turnover. Journal of Applied Psychology, 83(3), 486-493. https://doi.org/10.1037/0021-9010.83.3.486

Yeung, D. Y., Fung, H. H., \& Chan, D. K.-S. (2020). Roles of age and future time perspective of the work relationship in conflict management: A daily diary study. International Journal of Stress Management, 27(4), 358-369. https://doi.org/10.1037/str0000155

Zacher, H. (2020). Wellbeing and age in organisational life. In T. Wall, C. Cooper, \& P. Brough (Eds.), The SAGE handbook of organisational wellbeing. Sage.

Zacher, H., \& Frese, M. (2009). Remaining time and opportunities at work: Relationships between age, work characteristics, and occupational future time perspective. Psychology and Aging, 24(2), 487-493. https://doi.org/10.1037/a0015425

Zacher, H., Jimmieson, N. L., \& Bordia, P. (2014). Time pressure and coworker support mediate the curvilinear relationship between age and occupational well-being. Journal of Occupational Health Psychology, 19(4), 462-475. https://doi.org/10.1037/a0036995 
Table 1

Summary of Sample Characteristics

\begin{tabular}{|c|c|c|c|}
\hline & $\begin{array}{c}\text { Incomplete } \\
(\mathrm{N}=741)\end{array}$ & $\begin{array}{c}\text { Complete } \\
(\mathrm{N}=781)\end{array}$ & p-value \\
\hline \multicolumn{4}{|l|}{ Sex } \\
\hline Male & $349(47.1 \%)$ & $442(56.6 \%)$ & $<.001$ \\
\hline Female & $390(52.6 \%)$ & $339(43.4 \%)$ & \\
\hline Missing & $2(0.3 \%)$ & $0(0 \%)$ & \\
\hline \multicolumn{4}{|l|}{ Age (Years) } \\
\hline Mean $(\mathrm{SD})$ & $42.5(12.4)$ & $43.7(10.6)$ & .046 \\
\hline Median [Min, Max] & $42.0[18.0,78.0]$ & $44.0[19.0,74.0]$ & \\
\hline \multicolumn{4}{|l|}{ Professional Experience (Years) } \\
\hline Mean $(\mathrm{SD})$ & $14.0(11.1)$ & $15.5(11.4)$ & .019 \\
\hline Median [Min, Max] & $10.0[0,47.0]$ & $13.0[0,51.0]$ & \\
\hline Missing & $193(26.0 \%)$ & $17(2.2 \%)$ & \\
\hline \multicolumn{4}{|l|}{ Education } \\
\hline Primary School & $3(0.4 \%)$ & $0(0 \%)$ & .010 \\
\hline Lower Secondary School & $79(10.7 \%)$ & $49(6.3 \%)$ & \\
\hline Intermediate Secondary School & $250(33.7 \%)$ & $272(34.8 \%)$ & \\
\hline Upper Secondary School & $123(16.6 \%)$ & $141(18.1 \%)$ & \\
\hline College/University or Technical College & $275(37.1 \%)$ & $313(40.1 \%)$ & \\
\hline Missing & $11(1.5 \%)$ & $6(0.8 \%)$ & \\
\hline \multicolumn{4}{|l|}{ Monthly Household Income (Euros/Month) } \\
\hline Mean (SD) & $3160(3060)$ & $3500(4410)$ & .093 \\
\hline Median [Min, Max] & $2930[0,55000]$ & $3000[0,70000]$ & \\
\hline Missing & $195(26.3 \%)$ & $0(0 \%)$ & \\
\hline \multicolumn{4}{|l|}{ Industry } \\
\hline Health \& Social Services & $60(8.1 \%)$ & $80(10.2 \%)$ & .123 \\
\hline Information \& Communication & $55(7.4 \%)$ & $59(7.6 \%)$ & \\
\hline Manufacturing & $73(9.9 \%)$ & $91(11.7 \%)$ & \\
\hline Other Service Activities & $74(10.0 \%)$ & $76(9.7 \%)$ & \\
\hline Public Administration & $61(8.2 \%)$ & $107(13.7 \%)$ & \\
\hline Other & $247(33.3 \%)$ & $368(47.1 \%)$ & \\
\hline Missing & $171(23.1 \%)$ & $0(0 \%)$ & \\
\hline \multicolumn{4}{|l|}{ T1 Physiological Disease } \\
\hline Mean $(\mathrm{SD})$ & $0.42(0.76)$ & $0.64(0.85)$ & $<.001$ \\
\hline Median [Min, Max] & $0[0,3.00]$ & $0[0,3.00]$ & \\
\hline \multicolumn{4}{|l|}{ T1 Emotion Regulation } \\
\hline Mean $(\mathrm{SD})$ & $3.34(0.74)$ & $3.51(0.75)$ & $<.001$ \\
\hline Median [Min, Max] & $3.33[1.00,5.00]$ & $3.33[1.00,5.00]$ & \\
\hline Missing & $223(30.1 \%)$ & $0(0 \%)$ & \\
\hline \multicolumn{4}{|l|}{ T1 Perceived Remaining Time } \\
\hline Mean $(\mathrm{SD})$ & $2.87(0.96)$ & $2.79(0.91)$ & .124 \\
\hline Median [Min, Max] & $3.00[1.00,5.00]$ & $3.00[1.00,5.00]$ & \\
\hline Missing & $214(28.9 \%)$ & $0(0 \%)$ & \\
\hline
\end{tabular}


Table 2

Descriptive Statistics and Correlations

\begin{tabular}{|c|c|c|c|c|c|c|c|c|c|c|c|c|c|c|c|c|c|c|}
\hline & Variables & $\mathbf{n}$ & Mean & SD & 1. & 2. & 3. & 4. & 5. & 6. & 7. & 8. & 9. & 10. & 11. & 12. & 13. & 14. \\
\hline 1. & T1 Age & 781 & 43.704 & 10.641 & - & & & & & & & & & & & & & \\
\hline 2. & T1 Professional Experience & 764 & 15.471 & 11.381 & .640 & - & & & & & & & & & & & & \\
\hline 3. & T1 Sex $(1=$ male $; 2=$ female $)$ & 781 & 1.434 & .496 & -.019 & -.013 & - & & & & & & & & & & & \\
\hline 4. & T1 Education & 775 & 3.926 & 1.002 & -.162 & -.100 & -.102 & - & & & & & & & & & & \\
\hline 5 . & T1 Income (€/Month) & 781 & $3,503.73$ & $4,409.85$ & -.042 & -.010 & -.091 & .187 & - & & & & & & & & & \\
\hline 6. & T1 Physiological Disease & 781 & .639 & .849 & .329 & .233 & .090 & -.187 & -.038 & $(.473)$ & & & & & & & & \\
\hline 7. & T1 Emotion Regulation & 781 & 3.51 & .752 & .153 & .071 & -.076 & -.024 & .035 & .071 & $(.736)$ & & & & & & & \\
\hline 8. & T1 Remaining Time & 781 & 2.786 & .910 & -.669 & -.472 & .012 & .205 & .055 & -.342 & -.034 & $(.610)$ & & & & & & \\
\hline 9. & T2 Experienced Incivility & 781 & 1.607 & .799 & -.229 & -.153 & -.023 & .049 & .031 & .038 & -.073 & .082 & $(.905)$ & & & & & \\
\hline 10. & T3 Experienced Incivility & 781 & 1.588 & .803 & -.287 & -.216 & -.028 & .103 & .027 & -.010 & -.155 & .107 & .616 & $(.921)$ & & & & \\
\hline 11. & T2 Job Satisfaction & 781 & 4.643 & 1.014 & .170 & .111 & -.028 & .038 & .114 & -.012 & .183 & -.008 & -.295 & -.217 & - & & & \\
\hline 12. & T3 Job Satisfaction & 781 & 4.615 & 1.013 & .138 & .071 & -.009 & .074 & .055 & -.064 & .200 & .061 & -.182 & -.199 & .506 & - & & \\
\hline 13. & T2 Emotional Exhaustion & 781 & 2.645 & 1.059 & -.125 & -.061 & .055 & -.027 & -.076 & .082 & -.165 & -.013 & .378 & .305 & -.477 & -.385 & $(.934)$ & \\
\hline 14. & T3 Emotional Exhaustion & 781 & 2.559 & 1.061 & -.161 & -.089 & .056 & -.039 & -.065 & .082 & -.220 & .013 & .333 & .410 & -.404 & -.504 & .650 & $(.940)$ \\
\hline
\end{tabular}

Note. $r_{x y}>=|-.071|, p<.05$. T1 Remaining Time $=$ T1 Perceived Remaining Time. Where relevant (i.e., for multi-item scales),

coefficient alpha $(\alpha)$ reliability estimates appear in the diagonal. 
Table 3

Relevant Results of Structural Equation Model

\begin{tabular}{|c|c|c|c|c|c|c|c|}
\hline Outcome & Predictor & Estimate & SE & $\mathbf{Z}$ & p-value & $\begin{array}{c}95 \% \text { CI } \\
\text { Lower }\end{array}$ & $\begin{array}{c}95 \% \text { CI } \\
\text { Upper }\end{array}$ \\
\hline T1 Emotion Regulation & T1 Age & .011 & .003 & 4.380 & .000 & .006 & .016 \\
\hline T1 Physiological Disease & T1 Age & .009 & .001 & 7.000 & .000 & .006 & .011 \\
\hline \multirow[t]{8}{*}{ T2-T3 $\Delta$ Job Satisfaction } & T1 Emotion Regulation (ER) & .163 & .056 & 2.929 & .003 & .054 & .271 \\
\hline & T1 Physiological Disease (PD) & -.656 & .297 & -2.205 & .027 & -1.239 & -.073 \\
\hline & T1 Age & .009 & .004 & 2.339 & .019 & .001 & .016 \\
\hline & T2 Job Satisfaction & -.601 & .034 & -17.666 & .000 & -.668 & -.534 \\
\hline & T2 Emotional Exhaustion & -.175 & .037 & -4.705 & .000 & -.248 & -.102 \\
\hline & T2 Experienced Incivility (EI) & .018 & .041 & .435 & .664 & -.062 & .098 \\
\hline & $\mathrm{T} 1 \mathrm{ER} \times \mathrm{T} 2 \mathrm{EI}$ & .090 & .070 & 1.292 & .196 & -.047 & .227 \\
\hline & $\mathrm{T} 1 \mathrm{PD} \times \mathrm{T} 2 \mathrm{EI}$ & .027 & .142 & .194 & .847 & -.250 & .305 \\
\hline \multirow[t]{8}{*}{ T2-T3 $\Delta$ Emotional Exhaustion } & T1 Emotion Regulation (ER) & -.195 & .051 & -3.814 & .000 & -.295 & -.095 \\
\hline & T1 Physiological Disease (PD) & .606 & .272 & 2.226 & .026 & .072 & 1.139 \\
\hline & T1 Age & -.009 & .003 & -2.482 & .013 & -.015 & -.002 \\
\hline & T2 Job Satisfaction & -.081 & .031 & -2.604 & .009 & -.142 & -.020 \\
\hline & T2 Emotional Exhaustion & -.439 & .034 & -12.879 & .000 & -.506 & -.373 \\
\hline & T2 Experienced Incivility (EI) & .102 & .037 & 2.743 & .006 & .029 & .176 \\
\hline & $\mathrm{T} 1 \mathrm{ER} \times \mathrm{T} 2 \mathrm{EI}$ & .154 & .064 & 2.387 & .017 & .027 & .280 \\
\hline & $\mathrm{T} 1 \mathrm{PD} \times \mathrm{T} 2 \mathrm{EI}$ & -.135 & .138 & -.977 & .328 & -.405 & .135 \\
\hline
\end{tabular}

Note. $\mathrm{SE}=$ standard errors. $\mathrm{CI}=$ confidence interval. 
Figure 1

Conceptual Model

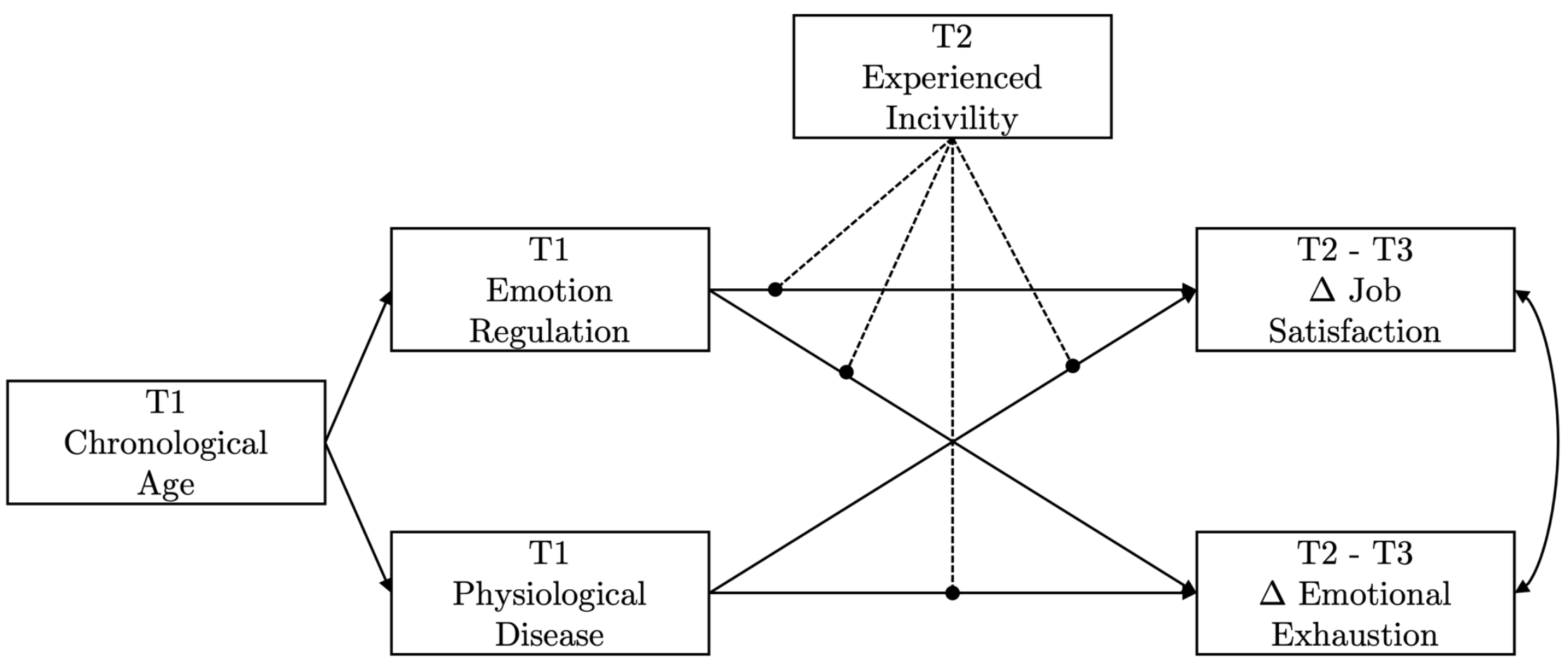

Note. Dashed lines indicate moderation. For the sake of parsimony, direct effects ("c'-paths") have been omitted in this conceptual representation. 
Figure 2

Relationship between Emotion Regulation and Emotional Exhaustion Moderated by Experienced Incivility

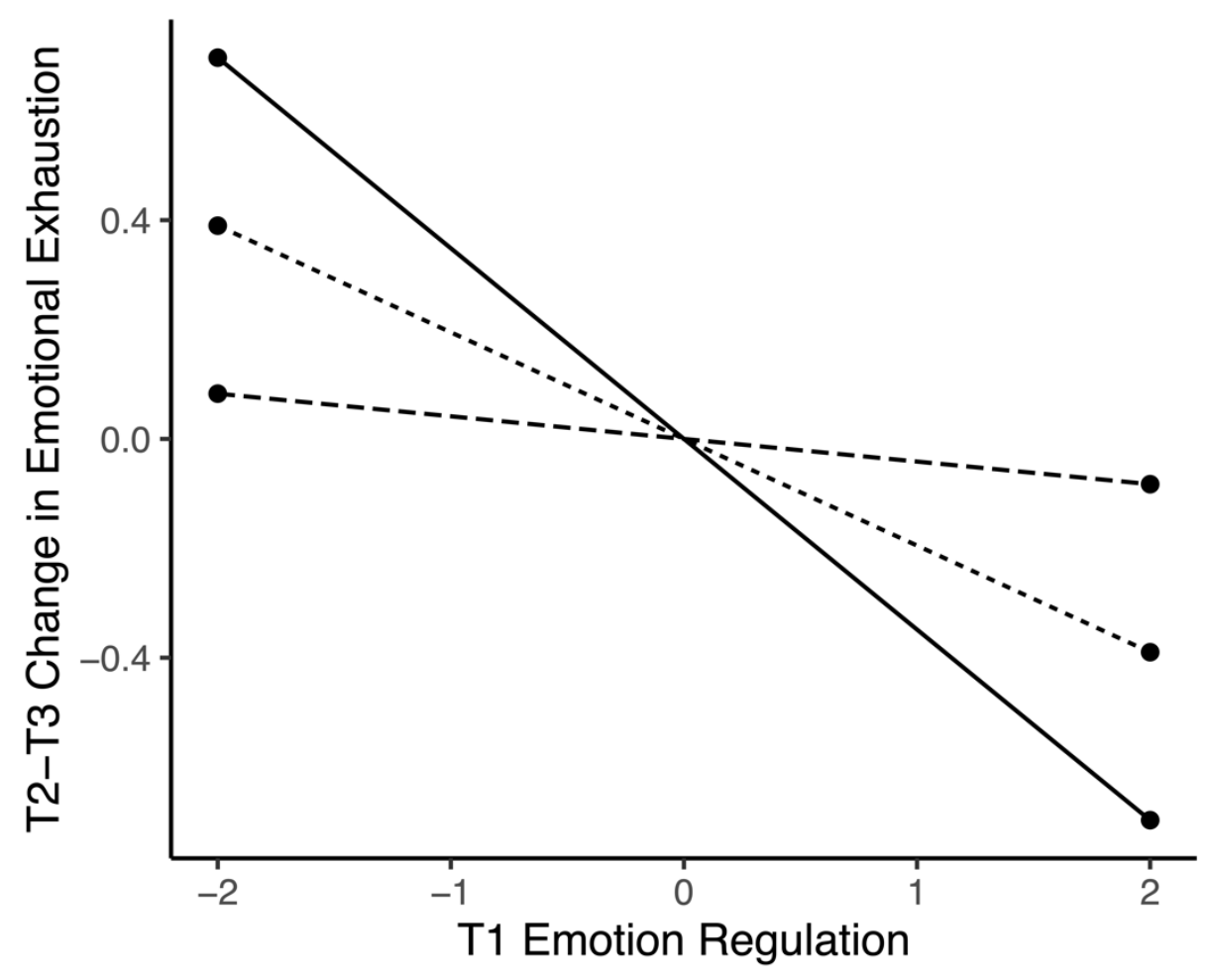

T2 Experienced Incivility

— Low Incivility (-1 S.D.)

-... Mean Incivility

--· High Incivility (+1 S.D.) 